\title{
A Compact Gas-Cooled Fast Reactor with an Ultra-Long Fuel Cycle
}

\author{
Hangbok Choi, Robert W. Schleicher, and Puja Gupta
}

General Atomics, P.O. Box 85608, San Diego, CA 92186-5608, USA

Correspondence should be addressed to Hangbok Choi; h.choi@ga.com

Received 24 October 2012; Accepted 14 March 2013

Academic Editor: Wei Shen

Copyright (c) 2013 Hangbok Choi et al. This is an open access article distributed under the Creative Commons Attribution License, which permits unrestricted use, distribution, and reproduction in any medium, provided the original work is properly cited.

\begin{abstract}
In an attempt to allow nuclear power to reach its full economic potential, General Atomics is developing the Energy Multiplier Module $\left(\mathrm{EM}^{2}\right)$, which is a compact gas-cooled fast reactor (GFR). The $\mathrm{EM}^{2}$ augments its fissile fuel load with fertile materials to enhance an ultra-long fuel cycle based on a "convert-and-burn" core design which converts fertile material to fissile fuel and burns it in situ over a 30-year core life without fuel supplementation or shuffling. A series of reactor physics trade studies were conducted and a baseline core was developed under the specific physics design requirements of the long-life small reactor. The EM ${ }^{2}$ core performance was assessed for operation time, fuel burnup, excess reactivity, peak power density, uranium utilization, etc., and it was confirmed that an ultra-long fuel cycle core is feasible if the conversion is enough to produce fissile material and maintain criticality, the amount of matrix material is minimized not to soften the neutron spectrum, and the reactor core size is optimized to minimize the neutron loss. This study has shown the feasibility, from the reactor physics standpoint, of a compact GFR that can meet the objectives of ultra-long fuel cycle, factory-fabrication, and excellent fuel utilization.
\end{abstract}

\section{Introduction}

Nuclear power has much to offer in addressing the nation's energy security needs in an environmentally acceptable manner. However, today's nuclear power has its own challenges in the management of nuclear waste from both the front end and back end of the fuel cycle, along with huge upfront financial investment and competing against other energy resourceselectricity generation cost. Currently, the most prevailing commercial reactor type is the Light Water Reactor (LWR), and it is expected that the advanced LWR will be introduced in the very near future based on proven technologies [1]. However, the International Atomic Energy Agency (IAEA) predicts that for the longer term the focus will be on innovative designs to provide increased benefits in terms of safety and security, nonproliferation, waste management, resource utilization, and economics, as well as to offer a variety of energy products and flexibility in design, siting, and fuel cycle options [2].

Small reactors are defined as reactors with an equivalent electric output of less than $300 \mathrm{MW}$. The small modular reactor has been developed since the 1950s when the United States (US) Army and Navy initiated research programs for the design and test of various small nuclear reactors [3]. The Army was interested in producing electricity in remote area, which included a transportable reactor by tractor trailer without dismantlement and a barge reactor transportable by sea. The Navy focused on development and deployment of nuclear power sources for warships and submarines. In 2008, more than 45 small- and medium-sized reactor concepts and designs were developed under the national or international Research and Development (R \& D) programs [4].

Though it is difficult for small reactors to compete economically under the same paradigm as large commercial reactors, the market situation of the small reactors will be different from those of large-capacity nuclear power plants. In other words, it will depend on demand for a better distributed electricity supply, better match between the capacity increment and investment, and flexibility in site selection or diversity of the products $[5,6]$. The IAEA addressed attractive features of innovative small reactors that might facilitate their 
progress in certain energy markets as follows:

(i) factory fabrication that reduces cost, shortens construction time, and improves quality control; reduced design complexity, impact of human factors, and operation and maintenance requirements;

(ii) lower absolute capital costs, as compared to large capacity plants; incremental capacity increase with sequential construction; reduced financial risk for the incremental increase of demand;

(iii) suitability for small electricity grids, including an option of autonomous operation; feasible nonelectric applications such as seawater desalination, district heating, and process heat;

(iv) improved safety due to smaller core size.

In addition, small reactors with a longer fuel cycle can further improve the plant economy and energy security. The potential incentives of long-life small reactors will be the reduced obligations for spent fuel and waste management and greater or easier nonproliferation assurances to the international community [7]. Many countries such as the USA, the Russian Federation, Japan, India, and Brazil have performed design studies of small reactors without refueling, which include water, sodium, lead-bismuth and gas-cooled reactors [8-14]. The liquid metal reactors have shown good performance of long-life operation because of a high conversion ratio and neutron yield owing to hardened neutron spectrum and transuranic fuel, respectively [15-17]. It is also possible to design a traveling wave type sodium-cooled fast reactor with a capacity of $1000 \mathrm{MW}$ electric, which can last more than 30 years with a single initial fuel loading [18].

General Atomics launched an innovative new gas-cooled fast reactor (GFR) program in 2009, named Energy Multiplier Module $\left(\mathrm{EM}^{2}\right)$. The reactor system is designed to have dual applications: electricity generation and high temperature heat source. The reactor is small and transportable and can be deployed in an established grid or as a stand-alone power source for an isolated area or a military base. The reactor will be operated for decades without refueling. The reactor core is designed to use nonradioactive nuclear waste, that is, depleted uranium (DU), along with low enriched uranium (LEU). This paper describes the physics design approaches and fuel cycle characteristics of the $\mathrm{EM}^{2}$.

\section{Design Approach and Tools}

2.1. Design Choices. The design choices and their linkage to cost factor are schematically shown in Figure 1. For the high temperature operation and high quality heat source, a gas coolant such as helium is most feasible. When compared to other coolants such as sodium, the helium coolant is inert, single phase, nonradioactive, and chemically stable against water, and no intermediate loop is required for thermal-toelectric energy conversion [19]. High temperature operation improves the thermal efficiency of the plant, which has a direct effect on the electricity generation cost; however, it requires use of high temperature material for the fuel and core structure.
Both the thermal and fast neutron spectrum reactors are feasible for the gas coolant. From the physics design viewpoint, it is recommended to maximize the fuel burnup to improve the fuel cycle economics with a reasonable amount of fissile material in the core. From this perspective, a fast neutron spectrum was chosen, under which fertile fuel can be converted into fissile fuel and burned in situ. All the actinides are effectively burned or transformed under the fast neutron spectrum, while fissile nuclides are mostly burned under the thermal neutron spectrum. To accommodate high fuel burnup, the fuel design should consider high irradiation swelling of the fuel, internal pressure buildup of the fuel rod due to fission gas release, material damage due to high energy neutrons, and so forth.

Both the small and large reactor options are feasible for the gas-cooled fast reactor, while the gas-cooled thermal reactor in general requires large moderator volume which results in a low power density of the core. From the economics viewpoint, small reactors mitigate financial risk owing to low upfront capital investment, and economic competitiveness can be achieved through a modular construction approach, moving a large portion of the construction work from site to factory, shortened site construction period, design simplification, and so forth. In order to achieve an ultra-long fuel cycle in the small reactor, high quality reflector materials are required to minimize the neutron loss and the core configuration needs to be optimized to maximize the fuel utilization.

2.2. Convert and Burn. The excess reactivity of the $\mathrm{EM}^{2}$ core is driven by the balance of fissile isotopes and fission product poisoning. Initially, the core is loaded with only uranium fuel, and therefore, fissile uranium produces most of the reactor power and burns quickly until fissile plutonium builds up. Under a very hard neutron spectrum, fertile uranium can also burn as shown in Figure 2. In fact, the amount of fertile fission is around $20 \%$ in the GFR which is a nonnegligible contribution to the excess reactivity of the core [20]. However, this also indicates that neutron spectrum softening significantly affects the fertile uranium fission contribution because of its high fission cross-section threshold around $1 \mathrm{MeV}$. Figure 3 compares the productionto-absorption cross section ratios $\left(\nu \sigma_{f} / \sigma_{a}\right)$ of major nuclides. It can be seen that the nuclear properties of fissile plutonium are strongly dependent on neutron energy. A harder neutron spectrum will lead to higher excess reactivity; this excess reactivity decreases as fission products build up during longlife operation.

2.3. Physics Tools and Models. For the physics design calculations, a lattice code MICROX is used to generate multigroup cross-sections of the fuel and structural materials [21]. MICROX is an integral transport theory flux spectrum code which solves the neutron slowing-down and thermalization equations for a two-region (particle and moderator) lattice cell. The nuclear data of MICROX consists of GAM data (99 groups between $14.9 \mathrm{MeV}$ and $0.414 \mathrm{eV}$ ) and GATHER data (101 energy mesh points below $2.38 \mathrm{eV}$ ) for the fast and thermal energy ranges, respectively [22, 23]. For the 


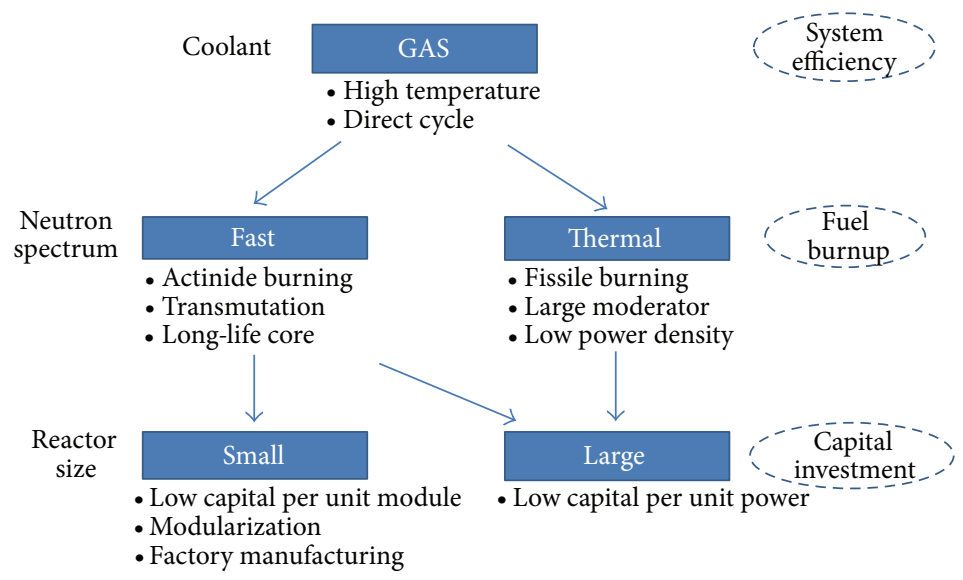

Figure 1: Design choices and economic factors.

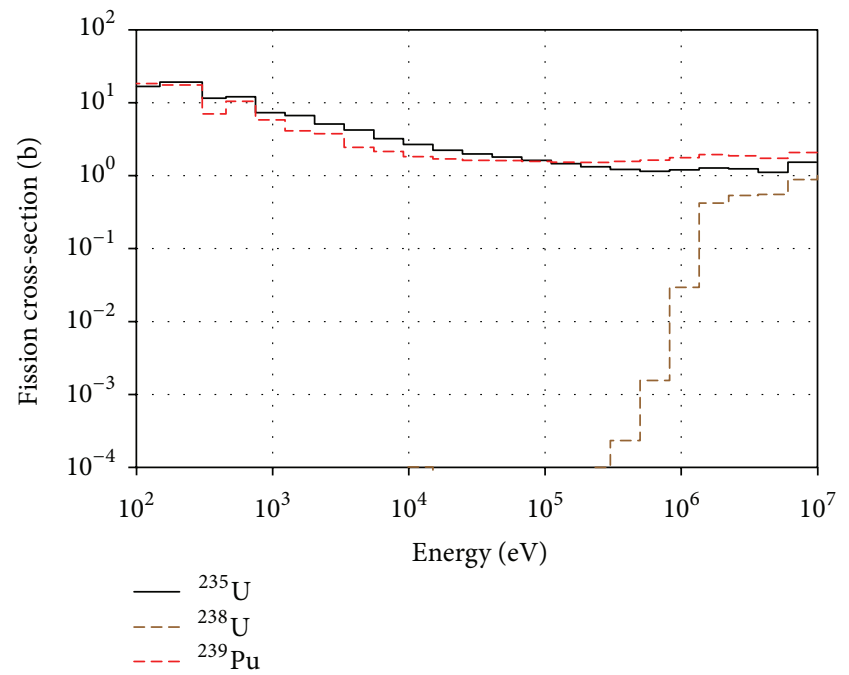

FIGURE 2: Fission cross-sections.

epithermal resolved energy range, the spectrum calculation uses GAR data with temperature-dependent cross sections [24].

The reactor core is analyzed by DIF3D and BURP for the static and depletion calculations, respectively [25, 26]. DIF3D is a multigroup steady-state neutron diffusion and transport code, which is used to calculate the eigenvalue (criticality) and power distribution of the core and to generate the neutron flux distribution to be used for the depletion calculation. The BURP code is also used to produce macroscopic cross sections of each core region using the microscopic cross sections and nuclide number densities, which are used by DIF3D for static diffusion calculations.

The actinide depletion chain used in the calculations is based on 20 nuclides and includes neutron capture, $(n, 2 n)$ reaction, and decay chains. Fission product yields have been generated for the fast reactor system based on JENDLE3.3 [27]. These yield data are available for ${ }^{232} \mathrm{Th},{ }^{233} \mathrm{U},{ }^{235} \mathrm{U}$,

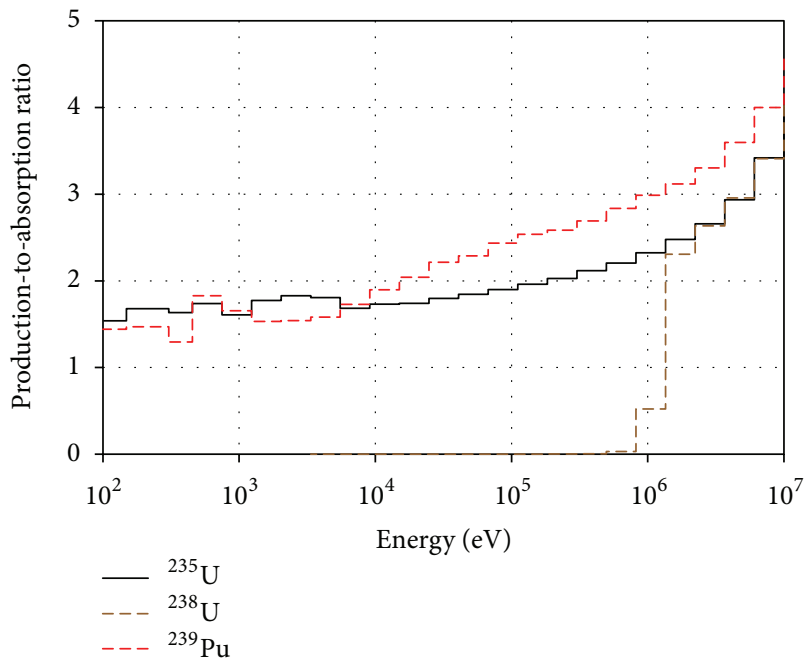

FIgURE 3: Production-to-absorption ratio.

${ }^{236} \mathrm{U},{ }^{238} \mathrm{U},{ }^{237} \mathrm{~Np},{ }^{239} \mathrm{Pu},{ }^{240} \mathrm{Pu},{ }^{241} \mathrm{Pu},{ }^{242} \mathrm{Pu},{ }^{241} \mathrm{Am}$, and ${ }^{243} \mathrm{Am}$. For example, direct yield data are provided for 1227 isotopes for $1 \mathrm{MeV}$ neutron fission of ${ }^{235} \mathrm{U}$. In order to obtain cumulative fission product yield, the decay chain has been prepared for $\sim 800$ isotopes for which the direct yield is greater than $10^{-10}$. The cumulative fission product yield has also been generated for 61 nonsaturating fission products (NSFP), and pseudofission products (PFP) were introduced to minimize the loss of fission products due to the truncated burn-up chain. The properties of PFP were obtained from an ORIGEN2.2 calculation [28].

The $\mathrm{EM}^{2}$ core is designed to release gaseous fission products in order to achieve a very high fuel burnup. Considering that the operating temperature of the reactor is high, it was assumed that not only the noble gases (Krypton and Xenon) but also other nuclides with a relatively low boiling temperature $\left(<450^{\circ} \mathrm{C}\right)$ are released during normal operation. For the physics design study, it was assumed that $70 \%$ of 
gaseous fission products are removed. The NSFP also contains gaseous fission products; the effective number densities for these materials were calculated by considering the reduction of absorption rate due to fission gas removal. The amount of gaseous fission products in the NSFP is $6 \%-8 \%$. If the removal rate of gaseous fission products is $70 \%$, for example, the inventory of saturating fission products and NSFP is reduced by $9.0 \%$ and $6.5 \%$, respectively, at the end-of-cycle, resulting in a $7.2 \%$ reduction of total fission product inventory [29].

The adequacy of using the legacy code system for the $\mathrm{EM}^{2}$ core depletion calculation was assessed in the earlier study especially for the prediction of peak excess reactivity and fuel cycle length [29] by the Monte Carlo code MCNPX with ENDF/B-VII.0 cross sections [30]. In general, the core excess reactivity is well predicted by the diffusion-based depletion model except for the initial core state where the maximum difference is $0.5 \% \delta k$. The differences of the peak excess reactivity and cycle length are less than $0.2 \% \delta k$ and 2 years, respectively. Currently the legacy code system is being updated for its cross section library and solution methods $[31,32]$.

\section{Physics Design Requirements}

A particular feature of $\mathrm{EM}^{2}$ physics design is that it aims for an ultra-long fuel cycle and a very high fuel burnup with a small reactor core size so that the fuel utilization is dramatically increased when compared to a commercial LWR. The principal requirements that guided the initial nuclear design studies are as follows.

(i) The nuclear reactor system shall have a design life of more than 20 years to enhance a high uranium utilization and fuel cycle economics.

(ii) There will be no refueling and fuel shuffling during the core life, and therefore, there will be no movement of either fresh or spent nuclear fuel materials to/from the reactor core.

Scoping analyses indicated that a heterogeneous core configuration is more favorable to obtain a longer fuel cycle when using fertile fuel. Therefore, the core will be composed of two distinctive fuel materials: the fissile starter (LEU) and fertile converter (DU). In order to fulfill the principal design requirements, the fissile enrichment, location, and size of the starter have been optimized under the physics design requirements given below.

3.1. Reactor Size. The reactor core size shall be limited by the maximum size of the reactor vessel that can be manufactured by competitive US fabricators and transported through special overspecified routes by special permit. The reactor vessel shall be sized to allow truck transport from the factory to the designated site. The reactor vessel shall be sized to include reactor core, reflector material, radiation shield, thermal shield, instrumentation, and control system. A guideline for maximum vessel size is 250 tons for component mass, $4.8 \mathrm{~m}$ for component diameter, and $30 \mathrm{~m}$ for component length, respectively.

3.2. Reactor Power. The reactor produces high temperature heat through controlled fission reactions in the fuel and regulates the rate of heat production to maintain a constant coolant outlet temperature in response to changes in coolant mass flow rate. The total reactor power is $500 \mathrm{MW}$ thermal, and the core outlet temperature shall be $850^{\circ} \mathrm{C}$. The power profile shall be flattened to reduce the peak fuel temperature. The fuel assembly peak power density shall be less than $200 \mathrm{~W} / \mathrm{cm}^{3}$ throughout the core life.

3.3. Fuel Management. The reactor operation time shall be maximized to enhance maximum overall fuel burnup. During the core life, the magnitude of excess reactivity shall be within the reactivity worth of the reactor control system with a sufficient margin, and the peak power density shall be kept below the $200 \mathrm{~W} / \mathrm{cm}^{3}$ design limit. The initial fissile enrichment averaged over the whole core including both the starter and converter fuel assemblies shall be minimized with a goal of overall enrichment close to that of the conventional LWR fuel. The plant life shall be at least 60 years and the fuel life shall be greater than 20 years at rated power without refueling or reshuffling.

3.4. Reactor Control System. The reactor core includes reactivity control systems that consist of multiple control drums strategically located in the reflector region and operating in banks. The reactor control system provides overall reactor power level and excess reactivity control. The reactor control system shall be designed to provide enough negative reactivity to maintain the controlled criticality of the core.

3.5. Reactor Shutdown System. The reactor core includes shutdown systems that are independently and adequately activated to rapidly shut down the reactor core under postulated accident conditions. The static and dynamic reactivity worth of the shutdown system shall be sufficient to terminate the reactivity and power transient following a reactor trip in response to a reactivity excursion accident such as a loss of coolant.

\section{4. $\mathrm{EM}^{2}$ Physics Performance}

The baseline core was selected through a series of parametric calculations of key design parameters: reactor size, fuel material type, matrix material type, fuel volume fraction, starter size and enrichment, reflector material and thickness, and so forth. The physics design calculations also incorporated some of the fuel and thermal-fluid design features such as fuel material chemical reaction, compatibility of the fuel material with clad, and cooling capability of the fuel. The baseline core model provides fundamental physics design values of $\mathrm{EM}^{2}$ so that follow-up calculations are performed for the fuel performance, reactor safety, and economics analyses. 
4.1. Baseline Core Model. The major components of the reactor system and coolant flow are shown in Figure 4. The reactor vessel is an internally insulated $4.7 \mathrm{~m}$ diameter, $10.6 \mathrm{~m}$ high structure constructed from standard SA533-Grade B plate steel. This vessel is of a size that can be manufactured by many vendors and is small enough to be shipped by truck to the construction site.

The $\mathrm{EM}^{2}$ baseline core, schematically illustrated in Figure 5, has a cycle length greater than 30 years without refueling, which means that the characteristics of the operating core simply depend on initial fuel loading. The baseline core is divided into three sections: starter, fertile, and reflector. The starter is the "critical" section of the reactor at beginning of life. It contains LEU to initiate criticality and provide excess neutrons for converting fertile to fissile materials in the fertile section. The core contains 85 fuel assemblies arranged in a hexagonal prism. Seventy-nine assemblies contain 91 fuel rods, each $2.7 \mathrm{~m}$ long by $20.5 \mathrm{~mm}$ in diameter. Six assemblies contain central voids for shutdown rod insertion. The clad is $1 \mathrm{~mm}$ thick $\beta$-SiC composite, which is highly resistant to both temperature excursions and neutron damage [33, 34]. The fuel is uranium carbide (UC) in the form of porous pellets. The interstitial pores allow room for fuel swelling and pathways for volatile fission products. The pellets are annular with a central hole that provides a means for volatile fission products to escape to a fission product collection system. This vented fuel in principle alleviates the pressure buildup and accommodates fuel swelling over the long core life.

The reflector consists of an inner section of canned $\mathrm{Be}_{2} \mathrm{C}$ and an outer section of graphite. These reflector materials are highly neutron economic and keep the neutron leakage from the core under $2 \%$. Due to power peaking around the core periphery, the starter fuel adjacent to the reflector has a reduced enrichment, leading to a radially flattened power profile that results in relatively uniform irradiation rates during the fuel cycle; this precludes the need for shuffling. Six rotatable drums are embedded in the reflector to provide reactivity control during normal operation.

4.2. Core Performance. The average fuel enrichment of the starter region is $11.4 \%$, which results in an average fissile content of $6.1 \%$ over the whole core. The $k_{\text {eff }}$ is shown in Figure 6, where the $k_{\text {eff }}$ initially increases up to 1.023 due to ${ }^{239} \mathrm{Pu}$ buildup in the starter region, and subsequently decreases due to ${ }^{235} \mathrm{U}$ depletion and fission product buildup. As ${ }^{239} \mathrm{Pu}$ also builds up in the converter region, $k_{\text {eff }}$ decreases slowly after $\sim 15$ years.

The core performance is summarized in Table 1 . The average discharge burnup is $145 \mathrm{GWd} / \mathrm{t}$ heavy metal (HM). The peak fuel burnup is $298 \mathrm{GWd} / \mathrm{tHM}$ for the starter fuel while the lowest fuel burnup is $48 \mathrm{GWd} / \mathrm{tHM}$ for the converter fuel located at the core edge region. The average fuel burnup of the starter and converter fuel is 192 and $95 \mathrm{GWd} / \mathrm{tHM}$, respectively. The inlet temperature is $500^{\circ} \mathrm{C}$ and the temperature rise in the core is $\sim 350^{\circ} \mathrm{C}$. Under this condition, the peak fuel temperature is estimated to be $1490^{\circ} \mathrm{C}$.
TABLE 1: Summary of $\mathrm{EM}^{2}$ baseline core performance.

\begin{tabular}{lc}
\hline Reactor power & $500 \mathrm{MW}$ thermal \\
Fuel material & Uranium carbide \\
Clad/structure material & Silicon carbide \\
Coolant material & Helium \\
Cycle length & 32 years \\
Average fissile content & $6.1 \mathrm{wt} \%$ \\
\hline Fuel loading & \\
$\quad$ Uranium & $42.8 \mathrm{t}$ \\
${ }^{235} \mathrm{U}$ & $2.6 \mathrm{t}$ \\
Fuel discharged & \\
$\quad$ Heavy metal & $36.7 \mathrm{t}$ \\
Uranium consumed & $23 \%$ \\
\hline Excess reactivity & $2.0 \% \delta \mathrm{k}$ \\
Peak/average burnup & $285 / 135 \mathrm{GWd} / \mathrm{t}$ \\
Peak/average power density & $165 / 58 \mathrm{~W} / \mathrm{cm}^{3}$ \\
Peak/average fast fluence $(>0.1 \mathrm{MeV})$ & $7.9 / 3.7 \times 10^{23} \mathrm{n} / \mathrm{cm}^{2}$ \\
\hline System pressure & $13.3 \mathrm{MPa}$ \\
System pressure (depressurized) & $0.45 \mathrm{MPa}$ \\
Core pressure drop & $25 \mathrm{kPa}$ \\
Core inlet temperature & $549^{\circ} \mathrm{C}$ \\
Core outlet temperature & $850^{\circ} \mathrm{C}$ \\
\hline
\end{tabular}

TABLE 2: Isotopic inventory $(\mathrm{kg})$ of $\mathrm{EM}^{2}$ baseline core.

\begin{tabular}{lccccc}
\hline & Charge & 10 years & 20 years & 30 years & Discharge \\
\hline${ }^{235} \mathrm{U}$ & 2,611 & 1,335 & 719 & 401 & 317 \\
${ }^{236} \mathrm{U}$ & 0 & 250 & 334 & 349 & 345 \\
${ }^{238} \mathrm{U}$ & 40,235 & 37,589 & 35,129 & 32,839 & 31,939 \\
${ }^{237} \mathrm{~Np}$ & 0 & 27 & 57 & 77 & 83 \\
${ }^{239} \mathrm{~Np}$ & 0 & 2 & 2 & 2 & 2 \\
${ }^{238} \mathrm{Pu}$ & 0 & 6 & 20 & 36 & 41 \\
${ }^{239} \mathrm{Pu}$ & 0 & 1,592 & 2,402 & 2,807 & 2,901 \\
${ }^{240} \mathrm{Pu}$ & 0 & 81 & 225 & 372 & 428 \\
${ }^{241} \mathrm{Pu}$ & 0 & 50 & 94 & 127 & 138 \\
${ }^{242} \mathrm{Pu}$ & 0 & 3 & 10 & 19 & 22 \\
${ }^{241} \mathrm{Am}$ & 0 & 6 & 17 & 31 & 37 \\
${ }^{242 \mathrm{~m}} \mathrm{Am}$ & 0 & 0 & 1 & 2 & 2 \\
${ }^{243} \mathrm{Am}$ & 0 & 0 & 1 & 2 & 2 \\
${ }^{242} \mathrm{Cm}$ & 0 & 1 & 1 & 2 & 2 \\
${ }^{243} \mathrm{Cm}$ & 0 & 0 & 0 & 0 & 0 \\
${ }^{244} \mathrm{Cm}$ & 0 & 1 & 3 & 7 & 9 \\
\hline $\mathrm{HM}$ & 42,846 & 40,942 & 39,016 & 37,073 & 36,271 \\
Fuel & 42,846 & 42,589 & 42,304 & 41,992 & 41,856 \\
\hline
\end{tabular}

The fuel inventory as a function of time is summarized in Table 2. Fissile material burning and production are shown in Figure 7 for ${ }^{235} \mathrm{U}$ and ${ }^{239} \mathrm{Pu}$. One of the design targets of the $\mathrm{EM}^{2}$ is to promote much higher uranium utilization than that of the conventional power reactors. In the case of $\mathrm{EM}^{2}$ once-through fuel cycle, the fissile uranium $\left({ }^{235} \mathrm{U}\right)$ 


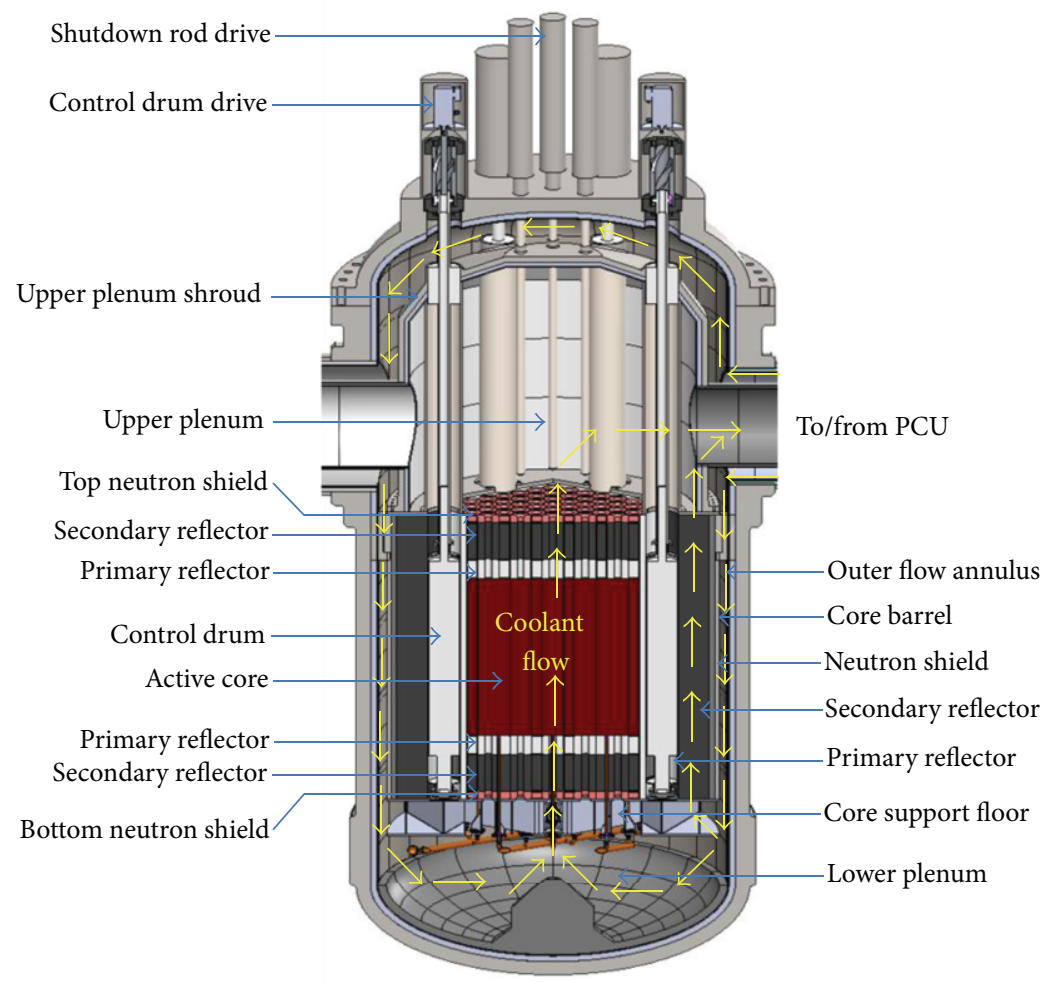

Figure 4: $\mathrm{EM}^{2}$ reactor system.

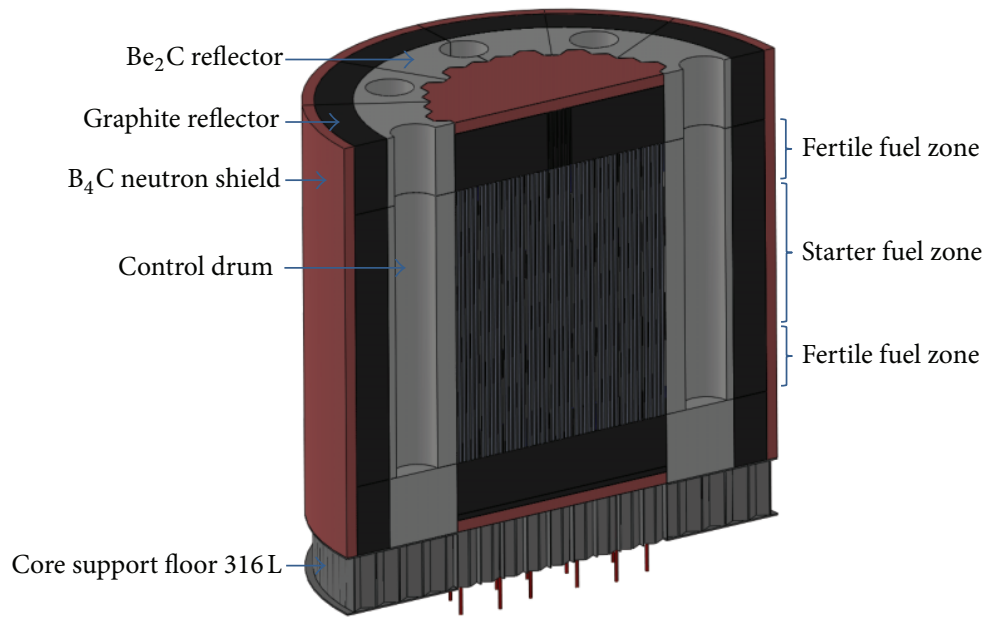

FIGURE 5: $\mathrm{EM}^{2}$ baseline core region.

is appreciably burned at the end of cycle (EOC) with an average consumption rate of $88 \%$, which was calculated based on initial loading and residual mass. The uranium was most effectively transmuted in the inner layer of the starter, resulting in the maximum consumption rate of $43 \%$ locally. The average uranium consumption over the whole core is $25 \%$. Figure 8 compares the fission rates of uranium with those of other nuclides and shows that the fertile uranium $\left({ }^{238} \mathrm{U}\right)$ contributes to the total fission rate by $18 \%$.
The $\mathrm{EM}^{2}$ core was designed to breed fissile plutonium and burn it. However, not all the fissile plutonium is burned at EOC and must be discharged. At EOC, the average fissile content (a fraction of ${ }^{235} \mathrm{U},{ }^{239} \mathrm{Pu}$, and ${ }^{241} \mathrm{Pu}$ out of total heavy metal) is $9.4 \%$. The amount of residual plutonium is $3.5 \mathrm{t}$, of which the fissile plutonium purity (a fraction of fissile plutonium out of total plutonium content) is $87 \%$. This has a high fuel value and will be recycled in the subsequent fuel cycles without conventional reprocessing [35]. 


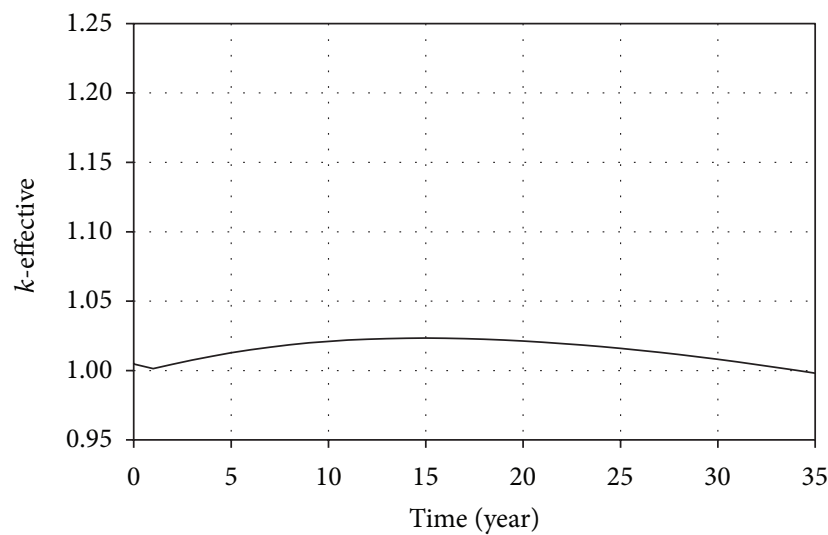

FIGURE 6: $k_{\text {eff }}$ of $\mathrm{EM}^{2}$ baseline core.

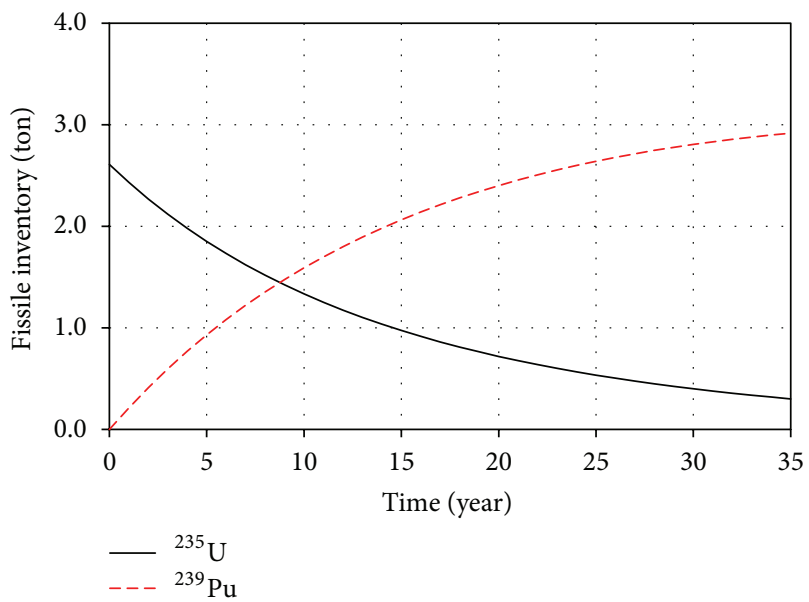

FIGURE 7: Fissile inventory change of $\mathrm{EM}^{2}$ baseline core.

TABLE 3: Comparison of mass flow for once-through fuel cycle.

\begin{tabular}{lcc}
\hline & ALWR & EM $^{2}$ \\
\hline Comparative power output, MWe & 1117 & 1117 \\
Number of units & 1 & 4.2 \\
Refueling period, year & 1.5 & 34 \\
Number of batches & 2.3 & 1 \\
Fuel burnup, GWd/tHM & 60 & 145 \\
60-year operation & & \\
$\quad$ (i) Heavy metal loading, ton & 1522 & 318 \\
$\quad$ (ii) Heavy metal discharge, ton & 1425 & 270 \\
\hline
\end{tabular}

4.3. Fuel Cycle Characteristics. The mass flow of the $\mathrm{EM}^{2}$ baseline core is compared to that of an advanced LWR (ALWR) based on fuel management parameters summarized in Table $3[36,37]$. The total electricity generation of $\mathrm{EM}^{2}$ was normalized to $1117 \mathrm{MW}$, which requires 4.2 units of $\mathrm{EM}^{2}$. For an operation period of 60 years, the amount of heavy metal loading and discharge is reduced by $\sim 80 \%$ in the ultra-long $\mathrm{EM}^{2}$ once-through fuel cycle when compared to ALWR oncethrough fuel cycle.

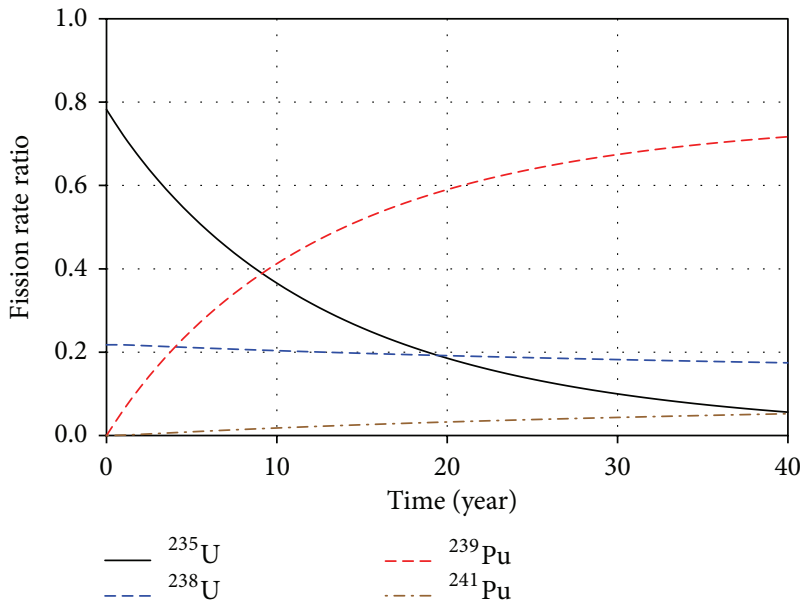

FIGURE 8: Fission rates of major nuclides.

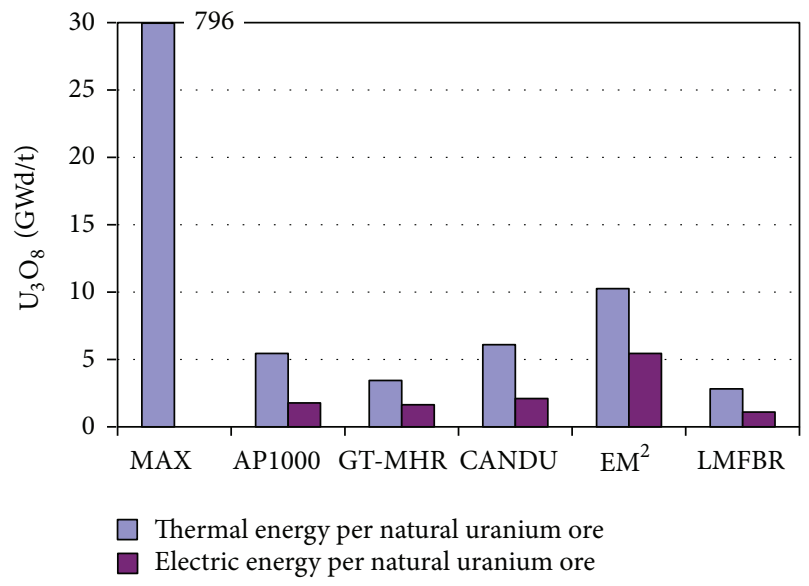

FIGURE 9: Comparison of energy per natural uranium ore.

The energy production per natural uranium ore is shown in Figure 9 for various reactor types including ALWR, gas turbine modular helium reactor (GT-MHR), Canadian deuterium uranium (CANDU) reactor, and liquid metal fast breeder reactor (LMFBR) [38-40]. The maximum energy obtainable from 1 ton of natural uranium $\left(\mathrm{U}_{3} \mathrm{O}_{8}\right)$ is estimated to be $796 \mathrm{GWd}$, if all uranium atoms fission and release $200 \mathrm{MeV}$ per fission. The amount of thermal energy produced per ton of natural uranium is $10.3 \mathrm{GWd}$ for the $\mathrm{EM}^{2}$, while it is $5.4 \mathrm{GWd}$ for the ALWR under the assumption that the fuel enrichment and fuel burnup are $4.8 \mathrm{wt} \%$ and $60 \mathrm{GWd} / \mathrm{tHM}$, respectively.

The amount of high level waste (used nuclear fuel) generated per energy production is shown in Figure 10 for $\mathrm{EM}^{2}$ and other reactors. The waste generation is the largest in the CANDU reactor due to the use of natural uranium fuel under a fully thermalized neutron spectrum. For the $\mathrm{EM}^{2}$, the waste generation is $5.8 \mathrm{kgHM} / \mathrm{GWd}$, while it is 15.6 $\mathrm{kgHM} / \mathrm{GWd}$ for the ALWR. 


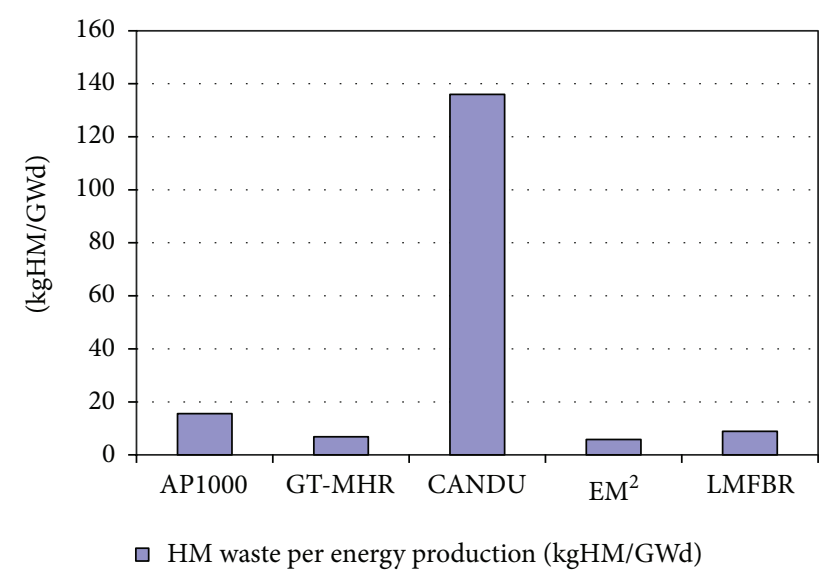

FIGURE 10: Comparison of waste per energy production.

TABLE 4: Comparison of unlevelized electricity costs.

\begin{tabular}{lcc}
\hline & ALWR & $\mathrm{EM}^{2}$ \\
\hline Number of cycles & 20 & 1 \\
Total electricity & $270 \mathrm{TWh}$ & $66 \mathrm{TWh}$ \\
Unit cost of fuel & $\sim 2,400 \$ / \mathrm{kgHM}$ & $\sim 4,760 \$ / \mathrm{kgHM}$ \\
Total fuel cost & $1,600 \mathrm{M} \$$ & $200 \mathrm{M} \$$ \\
Unlevelized average & $\sim 6 \$ / \mathrm{MWh}$ & $\sim 3 \$ / \mathrm{MWh}$ \\
\hline
\end{tabular}

4.4. Cost Estimation. Table 4 compares unlevelized electricity costs of $\mathrm{EM}^{2}$ and ALWR. The fuel cost of $\mathrm{EM}^{2}$ baseline core loading is estimated to be $\sim 200 \mathrm{M} \$$ which includes uranium ore, conversion, enrichment, assembly structures, and fabrication costs. This fuel generates 66 TWh electricity over 30 years at a capacity factor of $95 \%$. For the ALWR, total fuel cost is expected to be $\sim 1600 \mathrm{M} \$$ for 30 -year operation, including initial core loading. The corresponding total electricity generation will be $270 \mathrm{TWh}$ over 30 years. Therefore, the $\mathrm{EM}^{2}$ cycle yields a reduced fuel cycle cost when compared to the ALWR fuel cycle even though the unit fuel cost is expected to be higher for the $\mathrm{EM}^{2}(\sim 4,760 \$ / \mathrm{kgHM}$ on average) when compared to the ALWR fuel $(\sim 2,400 \$ / \mathrm{kgHM})$ [41]. It is also worth noting that the fuel is an upfront capital charge in $\mathrm{EM}^{2}$ as opposed to an operational charge in case of the ALWR.

A preliminary estimation of the electricity generation cost was made for $\mathrm{EM}^{2}$ and other power plants such as ALWR, coal, and natural gas plants, and the results are shown in Figure 11. The assumptions and methodology used for the cost estimation are consistent with the Department of Energy (DOE) GEN IV International Forum cost estimating guidelines [42], and the cash flow methodology is from Du and Parsons [41]. Specifically, the pertinent assumptions used for cost calculations of the $\mathrm{EM}^{2}$ and other technologies are as follows:

(i) the $\mathrm{EM}^{2}$ plant consists of 4 reactor modules, each with thermal rating of $500 \mathrm{MW}$, with a net plant efficiency of $53 \%$ and a capacity factor of $95 \%$; (ii) ALWR plant consists of a 1,117 MWe net electric rating with a capacity factor of $92 \%$ averaged over the life of the plant;

(iii) the costs are levelized over 60 years for the $n$ th-of-akind plant;

(iv) major financial parameters for nuclear and fossil fired plants include
(a) $50 \%$ debt at an $8 \%$ interest rate,
(b) $50 \%$ equity at a rate of $12 \%$,
(c) general inflation of $2.5 \%$ per year;

(v) enriched uranium cost is based on $95 \$ / \mathrm{kg}-\mathrm{U}_{3} \mathrm{O}_{8}$ feed, $6 \$ / \mathrm{kg}-\mathrm{U}_{3} \mathrm{O}_{8}$ conversion, and $165 \$ /$ Separation Work Unit (SWU) enrichment.

It can be seen that $\mathrm{EM}^{2}$ has a significant cost advantage over a comparable ALWR. It would break even with natural gas combined cycle plants at a natural gas price of 67 \$MMBtu. The $\mathrm{EM}^{2}$ cost advantage primarily comes from the compact equipment sizes, fewer components, significantly higher net plant efficiency, factory fabrication, and shorter field construction time. The $\mathrm{EM}^{2}$ overnight capital cost is 3,800 $\$ / \mathrm{kWe}$ versus $5,000-6,600 \$ / \mathrm{kWe}$ for ALWR plants. A single unit capacity addition is $\sim 1 \mathrm{~B} \$$ versus $\sim 5 \mathrm{~B} \$$ for ALWR. With the ability to add $\mathrm{EM}^{2}$ units as power demand grows, the financial risk associated with an $\mathrm{EM}^{2}$ plant substantially lower than a large ALWR can be achieved.

It should be noted that the uncertainty of the cost estimation is relatively large for the $\mathrm{EM}^{2}$ when compared to the commercial power plant, because the materials and manufacturing technologies are still being developed for the fuel, clad, structural components, and auxiliary systems of the $\mathrm{EM}^{2}$ while the market prices are well established for the commercial power plants.

\section{Summary and Recommendations}

The $\mathrm{EM}^{2}$ is a $500 \mathrm{MW}$ thermal GFR loaded with uranium carbide fuels, which satisfies physics design requirements of an ultra-long fuel cycle, high burnup, and compact reactor size, and is also economically competitive to large-scale commercial nuclear plants. These features offer new possibilities for fuel cycles to greatly improve fuel utilization and waste reduction, when compared to large-scale nuclear plants and other power sources. Nevertheless, there are many technical issues, which should be addressed and resolved through R \& $\mathrm{D}$ activities as follows.

In particular, it is required to resolve uncertainties associated with fission product buildup during the ultra-long fuel cycle with low excess reactivity.

Transient and safety analyses are required to confirm the controllability of excess reactivity and local power peaking throughout the fuel cycle.

Experimental verifications are required for the core criticality and fuel irradiation along with thermal-fluid and mechanical integrity tests. 


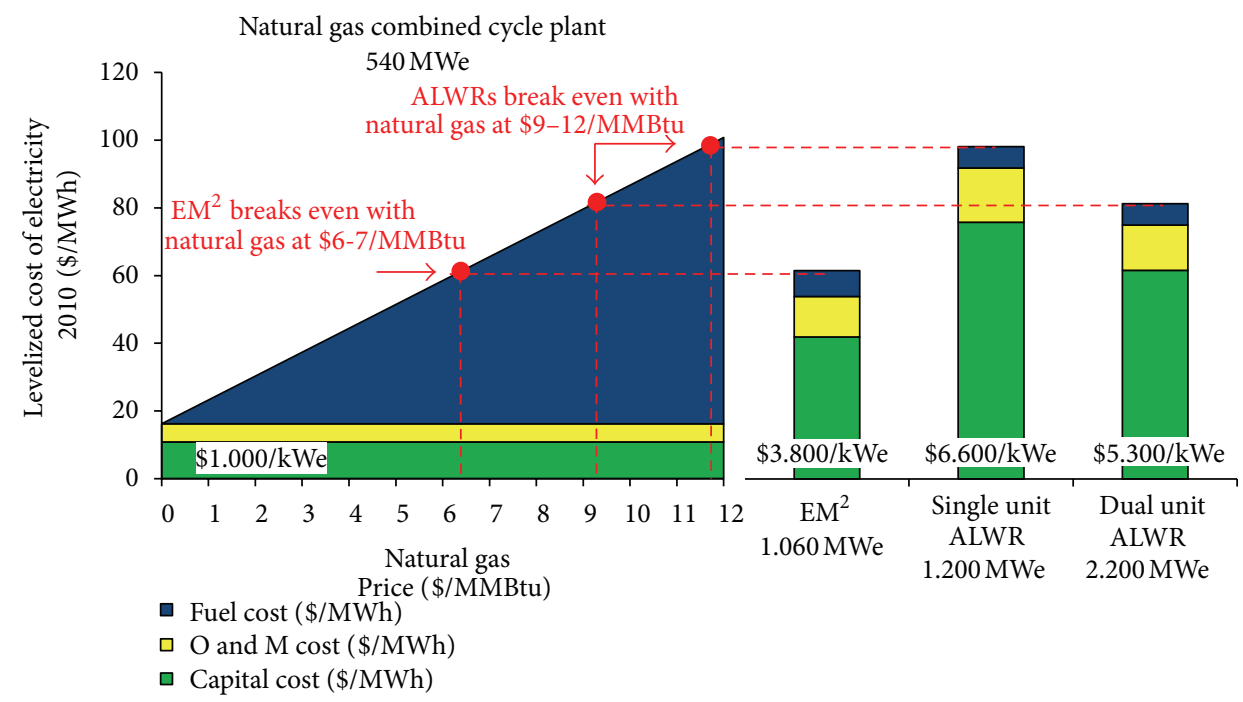

FIGURE 11: Comparison of $\mathrm{EM}^{2}$ power cost versus other generating options.

\section{Acknowledgment}

This work was supported by General Atomics internal funding.

\section{References}

[1] C. K. Paulson, "Westinghouse AP1000 electrical generation costs-meeting marketplace requirements," in Proceedings of the International Congress on Advances in Nuclear Power Plants (ICAPP '02), Hollywood, Fla, USA, 2002.

[2] "Innovative small and medium sized reactors: design features, safety approaches, and R\&D trends", IAEA-TECDOC-1451, International Atomic Energy Agency, 2005.

[3] Report to Congress on Small Modular Nuclear Reactors, U.S. Department of Energy, 2001.

[4] Design Features to Achieve Defense in Depth in Small and Medium Sized Reactors, Nuclear Energy Series no. NP-T-2.2, International Atomic Energy Agency, 2009.

[5] Status of Innovative Small and Medium Sized Reactor Designs 2005: Reactors with Conventional Refuelling Schemes, IAEATECDOC Series no. 1485, International Atomic Energy Agency, 2006.

[6] R. L. Black, "Small modular reactor U.S. market and licensing possibilities," in Proceedings of the American Nuclear Society Annual Meeting, Atlanta, Ga, USA, June 2009.

[7] Status of Small Reactor Designs without On-Site Refuelling, IAEA-TECDOC Series no. 1536, International Atomic Energy Agency, 2007.

[8] D. J. Senor, C. L. Painter, K. J. Geelhood et al., "A new innovative spherical cermet nuclear fuel element to achieve an ultra-long core life for use in grid-appropriate LWRs," PNNL-16647, Pacific Northwest National Laboratory, 2007.

[9] A. A. Belyaev, A. V. Kurachenkov, Y. K. Panov, and O. B. Samoilov, "Nuclear energy sources on the basis of integral reactors," Nuclear Engineering and Design, vol. 173, no. 1-3, pp. 131-141, 1997.

[10] K. Hibi, H. Takimoto, M. Chaki, M. Matsuura, and K. Moriya, "Development of the package-reactor (1) -reactor for pioneering new nuclear markets," Progress in Nuclear Energy, vol. 47, no. 14, pp. 115-122, 2005.

[11] M. Kambe, H. Tsunoda, K. Mishima, and T. Iwamura, "RAPIDL operator-free fast reactor concept without any control rods," Nuclear Technology, vol. 143, no. 1, pp. 11-21, 2003.

[12] F. Sefidvash, "Status of the small modular fluidized bed light water nuclear reactor concept," Nuclear Engineering and Design, vol. 167, no. 2, pp. 203-214, 1996.

[13] I. V. Dulera, A. Basak, P. P. Kelkar, and R. K. Sinha, "Compact high temperature reactor (CHTR)," in Proceedings of the 16th Annual Conference of Indian Nuclear Society (INSAC '05), Mumbai, India, November 2005.

[14] Z. Su'ud, "Advanced SPINNORs concept and the prospect of their deployment in remote area," in Proceedings of the International Conference on Advances in Nuclear Science and Engineering (ICANSE '07), Bandung, Indonesia, November 2007.

[15] Z. Su'ud and H. Sekimoto, "Preliminary design study of the ultra long life fast reactor," Nuclear Engineering and Design, vol. 140, no. 2, pp. 251-260, 1993.

[16] M. Kawashima, K. Aoki, K. Arie, and Y. Tsuboi, "Neutronic feasibility of an LMFBR super long-life core (SLLC)," Nuclear Engineering and Design, vol. 106, no. 3, pp. 357-373, 1988.

[17] T. K. Kim and T. A. Taiwo, "Feasibility study of ultra-long life fast reactor core concept," in Proceedings of the Advances in Reactor Physics to Power the Nuclear Renaissance (PHYSOR '10), pp. 1756-1766, Pittsburgh, Pa, USA, May 2010.

[18] J. Gilleland, C. Ahlfeld, D. Dadiomov et al., "Novel reactor designs to burn non-fissile fuels," in Proceedings of the International Congress on Advances in Nuclear Power Plants (ICAPP '08), Anaheim, Calif, USA, June 2008.

[19] A. E. Waltar and A. B. Reynolds, Fast Breeder Reactors, Pergamon Press, New York, NY, USA, 1981.

[20] P. Yarsky, Core design and reactor physics of a breed and burn gas-cooled fast reactor [Ph.D. thesis], Massachusetts Institute of Technology, 2005. 
[21] P. Wälti and P. Koch, "MICROX: a two-region flux spectrum code for the efficient calculation of group cross sections," General Atomic Report GA-A10827, Gulf General Atomic Company, 1972.

[22] G. D. Joanou and J. S. Dudek, "GAM II, a B3 code for the calculation of fast neutron spectra and associated multigroup constants," General Atomic Report GA-4265, Gulf General Atomic Company, 1963.

[23] G. D. Joanou, C. V. Smith, and H. A. Vieweg, "GATHER-II, an IBM-7090 code for the calculation of thermal neutron spectra and associated multigroup constants," General Atomic Report GA-4132, Gulf General Atomic Company, 1963.

[24] C. A. Stevens and C. V. Smith, "GAROL: a computer program for evaluating resonance absorption including resonance overlap," Tech. Rep. GA-6637, Gulf General Atomic Company, 1965.

[25] K. L. Derstine, "DIF3D: a code to solve one-, two-, and threedimensional finite difference diffusion theory problems," Tech. Rep. ANL-82-64, Argonne National Laboratory, 1984.

[26] R. Sherman, "PCBURP: a macroscopic cross section generation and nuclide depletion program for use with DIF3D," 21 C024, General Atomics, 1996.

[27] T. Nakagawa, H. D. Lemmel, and P. K. McLaughlin, "The JENDLE-3. 3 fission-product data library," IAEA-NDS-138, International Atomic Energy Agency, 2003.

[28] A. G. Croff, "A user's manual for the ORIGEN2 computer code," Tech. Rep. ORNL/TM-7175, Oak Ridge National Laboratory, 1980.

[29] H. Choi, "Physics model of a gas-cooled fast reactor: review and assessment," in Proceedings of the International Topical Meeting on Advances in Reactor Physics (PHYSOR '12), Knoxville, Tenn, USA, April 2012.

[30] D. B. Pelowitz, Ed., "MCNPXTM user's manual," Tech. Rep. LACP-05-0369, Los Alamos National Laboratory, 2005.

[31] J. Hou, K. Ivanov, and H. Choi, "MICROX-2 cross section library based on ENDF/B-VII," in Proceedings of the International Topical Meeting on Advances in Reactor Physics (PHYSOR '12), Knoxville, Tenn, USA, April 2012.

[32] J. Hou, K. Ivanov, and H. Choi, "Self-shielding models of MICROX-2 code," in Proceedings of the International Conference on Mathematics and Computational Methods Applied to Nuclear Science \& Engineering (M®C '13), Sun Valley, Idaho, USA, May 2013.

[33] L. L. Snead, T. Nozawa, Y. Katoh, T. S. Byun, S. Kondo, and D. A. Petti, "Handbook of $\mathrm{SiC}$ properties for fuel performance modeling," Journal of Nuclear Materials, vol. 371, no. 1-3, pp. 329-377, 2007.

[34] A. Kohyama, Y. Katoh, L. L. Snead, and R. H. Jones, "Development of $\mathrm{SiC} / \mathrm{SiC}$ composite for fusion application," in Proceedings of the 18th International Atomic Energy Agency Fusion Energy Conference, Sorrento, Italy, October 2000.

[35] H. Choi, D. W. McEachern, and R. W. Schleicher, "Energy Multiplier Module $\left(\mathrm{EM}^{2}\right)$ recycling fuel cycles," in Proceedings of the 1st Annual ANS SMR Conference, Washington, DC, USA, October-November 2011.

[36] W. E. Cummins, M. M. Corletti, and T. L. Schulz, "Westinghouse AP1000 advanced passive plant," in Proceedings of the International Congress on Advances in Nuclear Power Plants (ICAPP '03), Cordoba, Spain, May 2003.

[37] "Westinghouse-AP1000," Technology Fact Sheet, Westinghouse, 2008.
[38] C. Ellis, A. Baxter, and A. Shenoy, "Modular helium reactor fuel cycle concepts and sustainability," in Proceedings of the 2nd International Topical Meeting on High Temperature Reactor Technology (HTR '04), Beijing, China, September 2004.

[39] "Design manual: CANDU 6 generating station physics design manual," Wolsong NPP 23 4, 86-03310-DM-000 Rev. 1, Korea Atomic Energy Research Institute/Atomic Energy of Canada Limited, 1995.

[40] J. J. Duderstadt and L. J. Hamilton, Nuclear Reactor Analysis, John Wiley \& Sons, New York, NY, USA, 1976.

[41] Y. Du and J. E. Parsons, "Update on the cost of nuclear power," 09-004, Center for Energy and Environmental Policy Research, 2009.

[42] "Cost estimating guidelines for Generation IV nuclear energy systems, Revision 4.2," GIF/EMWG/2007/004, Generation IV International Forum, 2007. 


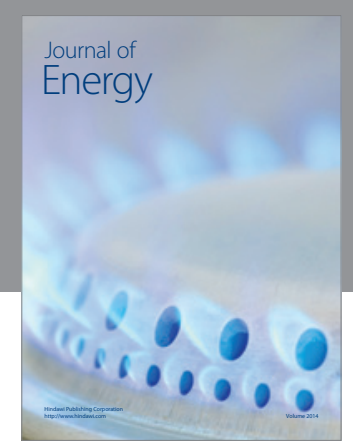

Journal of

Industrial Engineering
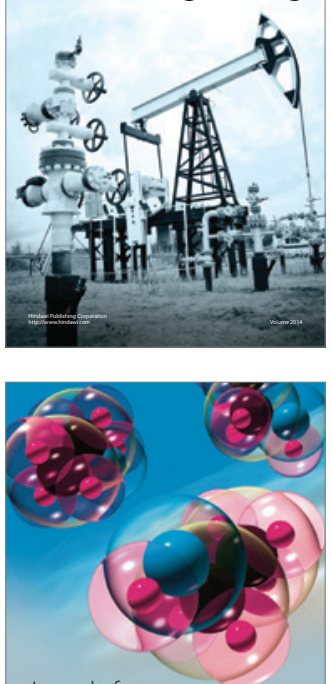

Fuels
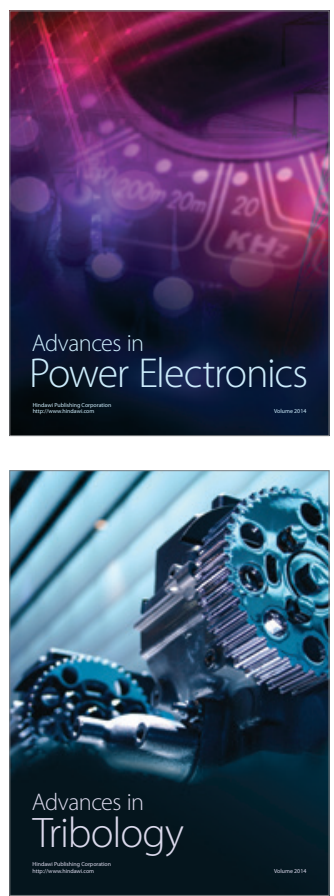

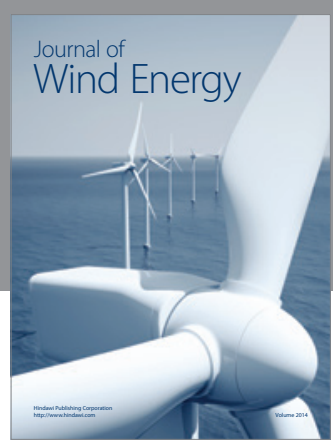

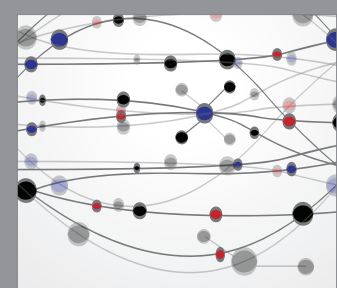

The Scientific World Journal

Submit your manuscripts at http://www.hindawi.com

Journal of

Structures
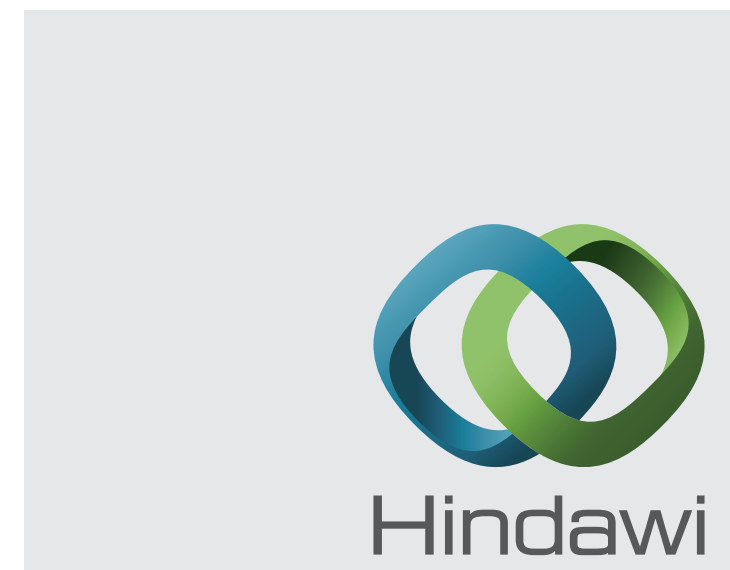

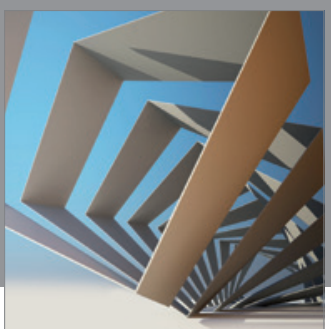

Rotating

Machinery
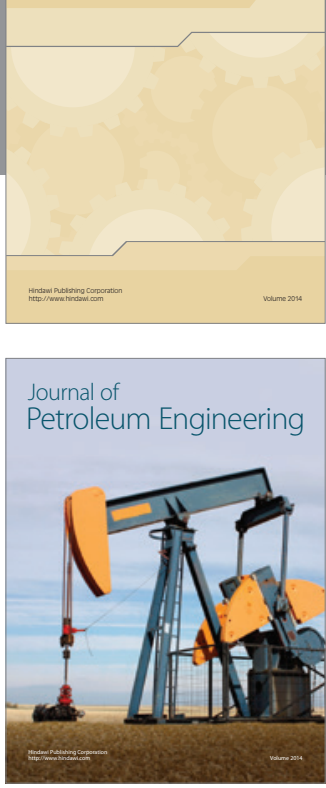

Journal of

Solar Energy
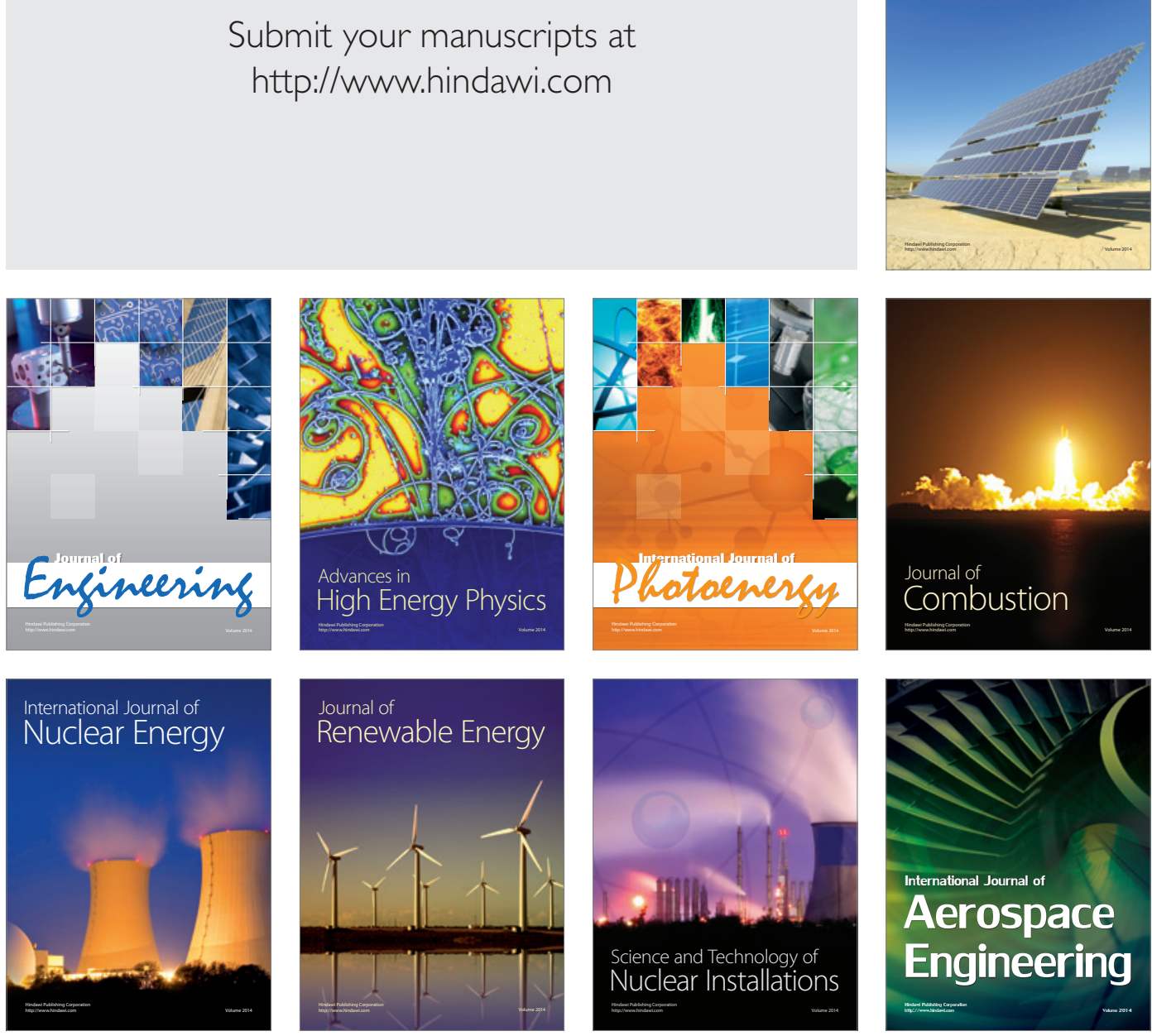